\title{
Meditation and Aerobic Exercise Enhance Mental Health Outcomes and Pattern Separation Learning Without Changing Heart Rate Variability in Women with HIV
}

\author{
Emma M. Millon ${ }^{1}$ (1) Paul M. Lehrer ${ }^{2} \cdot$ Tracey J. Shors $^{1,3}$ \\ Accepted: 3 December 2021 / Published online: 17 January 2022 \\ (c) The Author(s), under exclusive licence to Springer Science+Business Media, LLC, part of Springer Nature 2022
}

\begin{abstract}
Mental and physical (MAP) training targets the brain and the body through a combination of focused-attention meditation and aerobic exercise. The following feasibility pilot study tested whether 6 weeks of MAP training improves mental health outcomes, while enhancing discrimination learning and heart rate variability (HRV) in a group of women living with human immunodeficiency virus (HIV) and other stress-related conditions. Participants were assigned to training $(n=18)$ or notraining control $(n=8)$ groups depending on their ability and willingness to participate, and if their schedule allowed. Training sessions were held once a week for 6 weeks with $30 \mathrm{~min}$ of meditation followed by $30 \mathrm{~min}$ of aerobic exercise. Before and after 6 weeks of training, participants completed the Behavioral Pattern Separation Task as a measure of discrimination learning, self-report questionnaires of ruminative and trauma-related thoughts, depression, anxiety, and perceived stress, and an assessment of HRV at rest. After training, participants reported fewer ruminative and trauma-related thoughts, fewer depressive and anxiety symptoms, and less perceived stress $(p$ 's $<0.05)$. The positive impact on ruminative thoughts and depressive symptoms persisted 6 months after training. They also demonstrated enhanced discrimination of similar patterns of information $(p<0.05)$. HRV did not change after training $(p>0.05)$. Combining mental and physical training is an effective program for enhancing mental health and aspects of cognition in women living with HIV, although not necessarily through variance in heart rate.
\end{abstract}

Keywords HIV $\cdot$ Trauma $\cdot$ Rumination $\cdot$ Memory $\cdot$ Meditation $\cdot$ Exercise $\cdot$ Heart rate variability $\cdot$ Pattern separation

\section{Introduction}

Living with a chronic condition takes a toll on overall health and well-being. For example, the effects of human immunodeficiency virus (HIV) are widespread throughout the body including the brain, even with consistent regimes of antiviral medication (Asahchop et al., 2017; Kaul et al., 2001; Kovalevich \& Langford, 2012). As a result, people

Emma M. Millon

emma.millon@nyspi.columbia.edu

1 Behavioral and Systems Neuroscience, Department of Psychology, Rutgers University, Piscataway, New Jersey, USA

2 Department of Psychiatry, Rutgers-Robert Wood Johnson Medical School, Piscataway, New Jersey, USA

3 W.M. Keck Center for Collaborative Neuroscience, Rutgers University, Piscataway, New Jersey, USA with HIV experience chronic problems with central and peripheral nervous system function. Living with HIV also impacts mental health, particularly among women. Women with HIV are twice as likely to experience trauma compared to women without HIV (Machtinger et al., 2012). The diagnosis itself can elicit stress-related symptoms (Katz \& Nevid, 2005) as well as posttraumatic stress disorder, which accelerates viral progression (Hou et al., 2020). Up to $20 \%$ of women with HIV also meet criteria for major depressive disorder, which is four times higher than rates among non-HIV women (Morrison et al., 2002); they also are more likely to exhibit generalized anxiety disorder (Beer et al., 2019). Anxiety symptoms can exacerbate the likelihood of engaging in risk-taking behaviors (e.g., unprotected sex), living with unmet medical needs, and hospitalization (Beer et al., 2019). Health-related anxiety among women with HIV also contributes to difficulty sleeping and concentrating at school or work, as well as decreases in appetite (Schulte et al., 2018). Among women living with HIV, mental health 
issues can reduce access to HIV care and reproductive services (Orza et al., 2015).

In a previous study, we reported that women living with HIV were experiencing a relatively high degree of perceived stress in their everyday lives, as well as heightened symptoms of depression and anxiety (Millon \& Shors, 2021; Nightingale et al., 2010; Yanes et al., 2012). They also indicated that they were less likely to sense and trust bodily sensations (i.e., interoceptive awareness) and had difficulty regulating thoughts and feelings related to these sensations (Millon \& Shors, 2021). Black women with HIV in particular are at increased risk for major depression and suicidal behaviors, in part because they frequently experience gendered and racial discrimination (Thompson \& Dale, 2021). Health disparities contribute to HIV transmission and compromise access to care, particularly within racially minoritized Black and brown communities, where HIV is most prevalent (CDC, 2011). Racially minoritized individuals living with HIV also experience racial and economic discrimination and stigma from healthcare providers (Bird $\&$ Bogart, 2001), which can limit their access and adherence to care (Pellowski et al., 2013). Furthermore, racially minoritized women are more likely to live below the poverty line and experience inequity, which can increase risk of HIV transmission and reduce adherence to HIV treatment (Pellowski et al., 2013). Overall, these racial, social, and economic factors exacerbate the physical and mental health challenges of living with HIV.

Despite the alarming statistics on the mental and physical health challenges for HIV populations, there are few available interventions or lifestyle programs that are specifically designed for people with HIV (Hutton et al., 2020). The majority of behavioral health interventions are aimed at reducing transmission and improving antiretroviral therapy adherence. Some programs focus on targeting social contextual factors linked to HIV/AIDS that provide access to clean syringes, health care and stable housing, as poverty increases the risk of acquiring HIV (Adimora \& Schoenbach, 2005), but few interventions target mental health (Waldron et al., 2021). Among the intervention studies that do exist, participants are rarely followed over time, and therefore it is difficult to determine the long-term benefits. For example, cognitive-behavioral interventions reduce depression and anxiety in people with HIV but the follow-up period was brief (Spies et al., 2013).

In the present pilot study, we had the opportunity to provide an intervention to a small population of women living with HIV in the inner city of Newark, most of whom were middle-aged, lower socioeconomic status, and self-identified as Black. The program we offered is referred to as MAP Training because it combines mental and physical training. The mental training consists of $30 \mathrm{~min}$ of focused-attention meditation and the physical training consists of $30 \mathrm{~min}$ of aerobic exercise (Shors et al., 2014). Clinical and community studies indicate that the program, when practiced over weeks, can increase aspects of mental health, especially reducing symptoms of depression and the occurrence of ruminative thoughts. For example, women with sexual violence history who engaged in 6 weeks of MAP Training reported fewer numbers of ruminative and trauma-related cognitions, as well as greater self-worth (Millon et al., 2018; Shors \& Millon, 2016; Shors et al., 2018). In another study, women with substance dependence were less anxious and acquired greater cardiovascular fitness (measured as $\mathrm{VO}_{2}$ ) (Shors et al., 2014). In yet another study, the training decreased ruminative thoughts and depressive symptoms by $40 \%$ in adults with major depressive disorder, while increasing synchronized brain activity during tests for cognitive control (Alderman et al., 2016). The program also decreased perceived stress while increasing quality of life, this time in medical students (Lavadera et al., 2020). Recently, we reported that MAP Training reduced stress and improved well-being among school teachers during the COVID-19 pandemic (Demmin et al., 2021). Most importantly, the combination of meditation and aerobic exercise has been more effective for trauma and rumination than either activity alone (Shors et al., 2018). Importantly, MAP Training is not meant to be a substitute for psychotherapy or medication, but rather a behavioral health intervention that improves the fitness of the brain and body.

The MAP training program was adapted from laboratory studies indicating that mental and physical training activities in laboratory animals increase neurogenesis in the adult brain. In particular, Shors, Gould, and colleagues reported that mental training with standard learning procedures in rodents increased the survival of new neurons in the hippocampus (Gould et al., 1999), while other groups reported that physical training with aerobic exercise increased the number of new neurons that are generated in the hippocampus (van Praag et al., 1999). These findings were translated into the MAP Training program, with meditation as mental training and aerobic exercise for physical training (Millon \& Shors, 2019). Neurogenesis is not measurable in the human brain while someone is alive; however, MAP Training does not necessarily depend on changes in neurogenesis for its efficacy. In previous studies, we have determined that weekly training tends to decrease depression and anxiety as well as measures of rumination and stress (Alderman et al., 2016; Lavadera et al., 2020; Shors et al., 2014, 2018). So far, however, we have not identified the mechanisms through which the combination of mental and physical training enhances mental health. In laboratory studies, animals with fewer new hippocampal neurons are reportedly less able to discriminate very similar patterns of information, whereas animals with more neurogenesis were better able to discriminate between the patterns (e.g., Clelland et al., 2009; Drew et al., 2010; 
Snyder et al., 2005). These findings in animal models are supported by similar albeit indirect findings in humans (Bakker et al., 2008; Clelland et al., 2009; Kirwan et al., 2012; Lacy et al., 2011; Stark et al., 2013). Thus, we hypothesized that MAP Training would enhance discrimination learning, a process that could influence well-being in humans living with a chronic health condition.

It is reasonable to hypothesize that changes in autonomic nervous system (ANS) function may contribute. The MAP Training program activates both branches of the ANS, with most people experiencing a slow heartbeat during meditation, followed by a dramatic increase during aerobic exercise. Slow breathing during meditation increases baroreflex sensitivity and reduces sympathetic activity (Joseph et al., 2005). Conversely, high intensity aerobic exercise engages the sympathetic branch, with parallel increases in heart rate and arterial pressure via the baroreflex, thus allowing for increased blood pressure during exercise (Fu \& Levine, 2013). Dramatic changes in heart rate such as these reflect a healthy ANS that can respond quickly to danger as well as physical activity and rest (e.g., Shaffer \& Ginsberg, 2017). The general health of the ANS can be estimated by time variations between successive heartbeats or heart rate variability (HRV), which reflects cardiac flexibility and adaptability (Lehrer \& Eddie, 2013). Pathologies like HIV can impact HRV, such that heart oscillations become more regular and noncomplex, thereby increasing risk of illness or death (Lehrer \& Eddie, 2013). For example, people living with HIV experience hypersensitivity of the ANS as measured with cardiovascular reflex tests (e.g., Rogstad et al., 1999). There is also evidence that physical fitness is associated with greater HRV, as people with HIV who are more physically active exhibit lower resting heart rates, increased levels of maximal oxygen uptake, higher baroreflex sensitivity, and greater high-frequency HRV than those who are less physically active (Spierer et al., 2007). Thus, greater aerobic fitness (e.g., higher maximal oxygen uptake) might be related to higher HRV in people with HIV. However, very few studies have attempted to enhance physical health in people with HIV by targeting HRV with aerobic exercise. Black women with HIV particularly may benefit from aerobic exercise interventions that target HRV, as they exhibit significantly higher rates of abnormalities in cardiac structure and function (Mondy et al., 2011) relative to non-HIV Black women. These abnormalities are concerning because they are predictive of heart failure and all-cause mortality (e.g., Fisher et al., 2005).

HRV is measured from the electrocardiogram (ECG) or pulse, and then assessed according to time and/or frequency domains (Sayers, 1973; Shaffer \& Ginsberg, 2017; Task Force, 1996). Common time measurements include the standard deviation of normal beat-to-beat intervals or SDNN (in milliseconds), which tends to reflect general autonomic flexibility, and the root-mean-squared of standard deviation normal-to-normal or RMSSD, which reflects respiratory sinus arrhythmia, generally a measure of vagus nerve activity. Measurements related to frequency are assessed via power spectral analyses, which estimate variance in heart rhythms in specific frequency ranges (Stein \& Kleiger, 1999). In a healthy heart, the parasympathetic system predominates at rest and mediates both low $(0.04-0.15 \mathrm{~Hz})$ and high-frequency $(0.15-0.4 \mathrm{~Hz})$ oscillations, to the extent that cholinergic antagonists can reduce these responses (Akselrod et al., 1981; Billman, 2013; Reyes del Paso et al., 2013; Shaffer \& Ginsberg, 2017). The sympathetic system has minimal effects on high-frequency HRV, but drives the low end of the low-frequency range (Billman, 2013). Although the ratio between low and high-frequency activity has been cited as a measure of autonomic balance between sympathetic and parasympathetic branches (Pagani et al., 1984, 1986), there is evidence that it reflects parasympathetic function (Billman, 2013; Reyes del Paso et al., 2013). Low-frequency HRV in a range surrounding $0.1 \mathrm{~Hz}$ also can reflect activity of the baroreflex, which regulates blood pressure (Goldstein et al., 2011; Shaffer \& Ginsberg, 2017) via the brainstem (Gerlach et al., 2019), while projections from frontotemporal to limbic brain regions regulate changes in mood state (e.g., Schumann et al., 2021). In the present study, we assessed both low- and high-frequency activity during ECG recording before and after the 6-week MAP Training program. Our goal was to detect potential changes in ANS function that might account for potential increases in mental health outcomes. We assessed several canonical time (e.g., SDNN, RMSSD) and frequency (e.g., low-frequency, high-frequency, low/high frequency ratio) measures.

In the present study, we recruited women living with HIV, who ranged in age from young adulthood to elderly (e.g., 60 or above). Meta-analyses on physical exercise interventions for people with HIV report high adherence rates (e.g., 75\% or above) and document that exercise is safe and feasible (Dolan et al., 2006a; O'Brien et al., 2016). However, the majority of intervention studies tend to target men rather than women (Brown \& Vanable, 2008; Crepaz et al., 2014; Spaan et al., 2020). Although meditation studies for people with HIV have been effective at improving mental health, adherence rates can be low (e.g., Ramirez-Garcia et al., 2019a, 2019b). Given these data, we sought to determine whether a more comprehensive mental and physical training program targeting the brain and body was beneficial and feasible for women with HIV. 


\section{Method}

\section{Participants and Procedure}

Thirty-nine adult women with HIV $\left(M_{\text {age }}=45\right.$ years, range 22-68 years, 95\% Black/African-American, 2.5\% Latina, $2.5 \%$ White) were recruited from the François-Xavier Bagnoud Center and St. Clare's Housing Program in Newark, NJ. Inclusion criteria were: (1) women over age 18; (2) HIV-positive; (3) not engaged in a regular exercise program ( $<3$ days/wk for $20 \mathrm{~min}$ or less per session over the past month); (4) not engaged in any formal meditation practice (not meditating more than 30 min total per week and less than $200 \mathrm{~h}$ in lifetime); (5) free from physical limitations or contraindications to exercise; and (6) able and willing to provide informed consent. Exclusion criteria were those who were (1) pregnant; (2) had severe psychopathology; or (3) at high risk for suicide as determined by self-report questionnaires and the counseling supervisors at the site locations. If an individual met any of the exclusion criteria, she was compensated for her screening time and provided further resources as appropriate but did not continue further in the study.

At the start of the study, participants were attending group counseling, which continued throughout the MAP sessions; MAP was provided as an adjunct to participants' ongoing counseling and medication regimens. Following initial assessments, participants were scheduled for weekly MAP sessions for 6 weeks in a group setting. After training, participants returned for post-training assessments, and completed questionnaires 3 and 6 months post-training. Participants were assigned to training groups depending on their ability and willingness to participate, and if their schedule allowed. Training participants were compensated \$100 total for assessments and 6 weeks of training, and \$20 each for 3-month and 6-month follow-up testing. No-training controls who did not participate in the full course of training and only completed initial and follow-up assessments were paid up to $\$ 60$. Eleven women did not complete all test assessments and were omitted from data analyses; two of those were unable to return because of the COVID-19 pandemic and were compensated \$60. Eight out of 32 women who initially started in the MAP training group dropped out of training (adherence rate $\sim 75 \%$ ). Final groups numbers were $n=18$ for the training group and $n=8$ for no-training controls. All participants provided written informed consent in accordance with the Declaration of Helsinki. Procedures were approved by the Institutional Review Board at Rutgers University. All research staff were certified by the Collaboration Institutional Training Initiative (CITI) for Human Subjects Research.

\section{Measures}

After consent, participants were assessed on outcomes as follows:

- Trauma history: the history of traumatic events was assessed with the Life Events Checklist for DSM-5 (LEC-5; Weathers et al., 2013). The LEC assesses exposure to 16 events related to stress and trauma, including physical and sexual assault.

- Ruminative thoughts: the frequency and type of ruminative thoughts were assessed with the Ruminative Responses Scale (RRS; Treynor et al., 2003). The RRS measures how often a person engages in repetitive thoughts related to the past, blame, brooding, depression, and sadness. Scores range from 22 to 88 . Healthy young adults self-report rumination scores averaging around 42-44, women with sexual violence history report average scores in the 50's, and depressed individuals report scores closer to or above 60 (Millon et al., 2018; Nolen-Hoeksema et al., 1999; Shors et al., 2017).

- Depressive symptoms: the Beck Depression InventoryII (BDI-II; Beck et al., 1996) assessed the severity of depressive symptoms related to sadness, guilt, and changes in appetite/weight/interest in sex. BDI scores from 0-13 indicate minimal depression, 14-19 indicate mild depression, 20 and above indicate moderate to severe depression (Beck et al., 1996).

- Perceived stress: the Perceived Stress Scale (PSS; Cohen et al., 1983) assessed a person's self-reported ability on how well she could handle events in the past month. PSS scores ranging from $0-13$ are considered low perceived stress, 14-26 indicate moderate perceived stress, and 27-40 indicate high perceived stress.

- Postraumatic cognitions: thoughts and emotions related to a very stressful past event were assessed with the posttraumatic cognitions inventory (PTCI; Foa et al., 1999). Higher PTCI scores (i.e., greater than 130) are indicative of more posttraumatic cognitions and are associated with greater numbers of PTSD symptoms (Foa \& Rauch, 2004). The prompt was altered to reflect responses to a very stressful event rather than a traumatic event, because not all participants had experienced a traumatic life event.

- Anxiety symptoms: the Beck Anxiety Inventory (Beck et al., 1988) has been used in clinical populations to assess somatic and cognitive symptoms of anxiety. BAI scores less than 10 indicate minimal anxiety, 10-19 indicate mild to moderate anxiety, and greater than 20 indicate severe anxiety.

- Discrimination learning: participants completed the Behavioral Pattern Separation (BPS) task, also referred to as the Mnemonic Similarity Task (Bakker et al., 
2008; Stark et al., 2013). During the initial encoding phase, participants categorized 128 common objects as "indoor" or "outdoor" with a button press. Immediately following, participants were given a surprise recognition test in which they were shown repetitions of previously-viewed objects (64 targets), objects similar but not identical to those in the prior set (64 lures), and novel objects (64 foils). Participants were asked to categorize the items as "old", "similar", or "new" with a button press. There were two versions of the BPS task. Participants completed version A prior to training and version $B$ after training. Both versions contained everyday household objects but versions A and B included different objects so as to avoid practice effects.

- Heart rate variability (HRV). HRV was assessed while recording ECG during a 5-min rest period.

- Rest period procedure. During the rest period, participants were instructed to breath normally and count their breaths to themselves. If they lost count, they were instructed to begin counting again at one. The researcher alerted participants that they would be asked for the highest number of breaths counted at the end of the session. When the researcher verbally cued the participant, she began counting in silence until the researcher instructed the person to stop five minutes later. The researcher recorded the number of breaths the participant counted. Upon completion of the breathing task, electrodes were removed. This breathing exercise served to focus the participants' attention on their breath, and mimicked the practice engaged during MAP Training.

\section{MAP Training Intervention}

Each MAP training session began with 20 min of silent seated meditation, followed by $10 \mathrm{~min}$ of very-slow walking meditation, ending with $30 \mathrm{~min}$ of aerobic exercise. During the seated meditation component, participants were instructed to sit on the floor on a zafu pillow or on the edge of a straight-backed chair, with their upper torso upright. They were then instructed to place their hands together in their lap, with their right hand on the bottom and thumbs slightly touching. They were asked to either close their eyes or gaze at the floor a few feet in front of them. The participants were instructed to take a deep breath and then to focus their attention on their breath, noticing as the air travelled into and out of their body. They were instructed to breath normally while counting the pauses between the exhale and the inhale. They were to begin counting at one and when they lost count, instructed to return counting again at one. A timer was set for $20 \mathrm{~min}$.

When the timer sounded, participants were instructed to move their legs around to get oxygen flowing again and then to stand up and gather in a circle, facing in one direction. Participant were asked to focus their attention in their feet as they walked slowly in a circle, with their arms clasped loosely behind their back. Again, as their attention drifted from the point of focus, participants were instructed to notice the interruption in concentration, and return their attention to their feet. A timer was set for $10 \mathrm{~min}$.

When the timer sounded, participants were instructed to place their fingers alongside their neck and to count the number of pulses in $10 \mathrm{~s}$. This number was multiplied by 6 to estimate resting heart rate. Immediately following, participants engaged in a group aerobic exercise class to popular music. The choreographed exercise routines included kicking, jumping, and running in place. Participants who could not engage in high-impact activity were asked to move their arms rapidly up and down above their heads, as done during a jumping jack but without using the legs. After about 20 min of exercise, participants again took their own heart rate using their finger pressed at the neck and were encouraged to achieve at least $60 \%$ of their maximum. This number is calculated by subtracting age from 220 and multiplying by 0.6. The session ended with a $5 \mathrm{~min}$ cool-down, with stretching and slow walking in a circle to music.

\section{Data Analyses}

Mental health outcomes were analzyed using the SPSS statistical package (IBM, 2019). Repeated measures analyses of variance (ANOVAs) were conducted to determine whether RRS, BDI, PTCI, PSS, and BAI scores measured at the second assessment significantly differed from scores at initial assessment (alpha $=0.05)$ in those who trained $(n=18)$ as compared to no-training controls $(n=8)$.

Discrimination learning during the pattern separation task was analyzed with percent accuracy scores in response to the novel, old, and similar items. Novelty detection was calculated as the percent of novel items correctly rated as "new." The recognition memory score was calculated as the percent of familiar objects correctly rated as "old" minus the percent of new objects incorrectly rated as "old" (i.e., hits minus false alarms). Higher recognition memory scores indicated better recognition memory ability. Repeated measures ANOVAs were performed to determine whether post-training scores changed significantly after the 6-week MAP Training program. Data from participants who performed better than $80 \%$ on the recognition memory part of the task $(n=8)$ were further analyzed for pattern separation, which was calculated as the difference between the percent of similar objects correctly rated as "similar" minus the percent of novel objects incorrectly rated as "similar." Pattern separation ability is considered a higherorder cognitive process than recognition memory as individuals who are able to perform well on recognition memory are 
not always able to complete pattern separation tasks (e.g., Stark et al., 2013). In general, a higher pattern separation score indicated greater discrimination learning. A negative score would emerge if a participant incorrectly categorized more novel objects as "similar" than correctly categorized similar objects as "similar."

To analyze HRV, ECG data were collected from the wrists using a J\&J Engineering C2 + physiograph. Raw ECG data were digitized at 1024 samples per second and imported to WinCPRS ${ }^{\circledR}$ (Absolute Aliens Oy, Turku, Finland) or ARTiiFACT (Kaufmann et al., 2011) to extract time intervals between R-R waves (one heartbeat to the next) or interbeat (IBI) intervals. Kubios HRV software was used to analyze events during beat-to-beat intervals as follows (Tarvainen et al., 2014): standard deviation of normal-to-normal interbeat intervals (SDNN; msec), root-mean-square of differences between successive normal-to-normal interbeat intervals (RMSSD; msec), low-frequency power ( $\mathrm{msec}^{2}$ ), high-frequency power $\left(\mathrm{msec}^{2}\right)$ and the ratio of low-/high-frequency HRV. R-waves were visually inspected for movement artifacts or electrical noise for each participant in Kubios. Three participants' data were removed from analyses due to movement or noise, leaving a sample of 15 for analysis. HRV measures were normalized using log transformations. Paired t-tests were performed to determine whether HRV outcomes significantly changed after training when compared to before training $(n=15)$.

\section{Results}

\section{Trauma History and Mental Health Outcomes}

Eighteen women (67\%) reported a history of physical and/ or sexual assault whereas nine women (33\%) reported no history, as assessed with the LEC. Prior to the MAP Training program, mental health outcome measures extracted from the BDI, BAI, PSS, PTCI were not different between groups, $p$ 's $>0.05$. However, RRS scores at baseline were significantly higher among no-training controls $(M=49$, $S E=4)$ when compared to those in the training group prior to the intervention $(M=35, S E=5), p=0.03$.

There was a significant interaction between training group and time for both RRS (ruminative thoughts) and BDI (depressive symptoms) scores. RRS scores decreased by $19 \%$ post-training $(M=40, S E=3)$ versus pre-training $(M=49, S E=4),\left[F_{(1,24)}=17.37, p=0.00\right.$, partial $\left.\eta^{2}=0.42\right]$. (Fig. 1A). BDI scores decreased by $41 \%$ post-training $(M=11, S E=2)$ versus pre-training $(M=19, S E=2),\left[F_{(1,24)}=4.83, p=0.04\right.$, partial $\left.\eta^{2}=0.17\right]$ (Fig. 1B).

Pairwise comparisons indicated PSS (perceived stress) scores were reduced post-training $(M=14, S E=2)$ versus pre-training $(M=18, S E=2),\left[F_{(1,24)}=8.87, p=0.01\right.$, partial $\eta^{2}=0.27$ (Fig. 1C) but not for those who did not train $(p=0.21)$. There was not a significant group by time interaction for PSS scores, $p=0.41$. Pairwise comparisons indicated PTCI (post-traumatic thoughts) scores were reduced $17 \%$ post-training $(M=86, S E=7)$ versus pretraining $(M=104, S E=8),\left[F_{(1,24)}=6.67, p=0.02\right.$, partial $\eta^{2}=0.22$ (Fig. 1D) but not for those who did not train $(p=0.25)$. There was not a significant group by time interaction for PTCI scores, $p=0.54$. Similarly, MAP Training reduced the BAI (anxiety) scores by approximately 33\%, when comparing post-training $(M=10, S E=2)$ to pretraining $(M=15, S E=3),\left[F_{(1,24)}=4.99, p=0.04\right.$, partial $\eta^{2}=0.17$ (Fig. 1E). There was not a significant group by time interaction for BAI scores, $p=0.15$.

RRS, BDI and PSS scores were re-assessed 3 months $(n=17)$ and 6 months $(n=6)$ following the end of training. (PTCI and BAI scores were not assessed at 3-month and 6-month follow-up to reduce participant burden). The decrease in RRS scores remained significant at 6-month follow-up $(M=36, S E=5), t(5)=2.89, p=0.03$, Cohen's $d=1.18$ but not at 3-month follow-up $(M=42, S E=3)$, $p=0.24$. However, scores were reduced by $16 \%$ at 3 -month follow-up and by $27 \%$ at 6 -month follow-up (Fig. 2A). The decrease in BDI scores remained at 3-month $(M=10$, $S E=2), t(16)=3.79, p=0.002$, Cohen's $d=0.76$, and 6-month $(M=8, S E=3), t(5)=3.57, p=0.016$, Cohen's $d=1.21$, follow-up, with a nearly $50 \%$ decrease at 3 -month follow-up. The reduction in perceived stress after training was not sustained at 3-month or 6month follow-up (Fig. 2C).

\section{Discrimination Learning with a Pattern Separation Task}

Novelty detection accuracy (the percentage of correct responses to novel objects) and pattern separation accuracy (the percentage of correct responses to similar objects) scores did not significantly differ between groups before training, $p$ 's $>0.05$ (Table 1 ). Novelty detection accuracy did not significantly change after training $(M=0.62, S E=0.06)$ compared to before training $(M=0.70, S E=0.05)$, $F_{(1,22)}=0.55, p=0.47$, partial $\eta^{2}=0.02$ (Fig. 3B). Participants who were at least $80 \%$ accurate during recognition memory were selected for further analyses $(n=8)$ and their pattern separation scores increased after training, $t(7)=-2.53, p=0.04$, Cohen's $d=0.89$ (Fig. 3C). Correlations between the pattern separation scores and mental health outcomes were not significant ( $p$ 's $>0.05)$. 

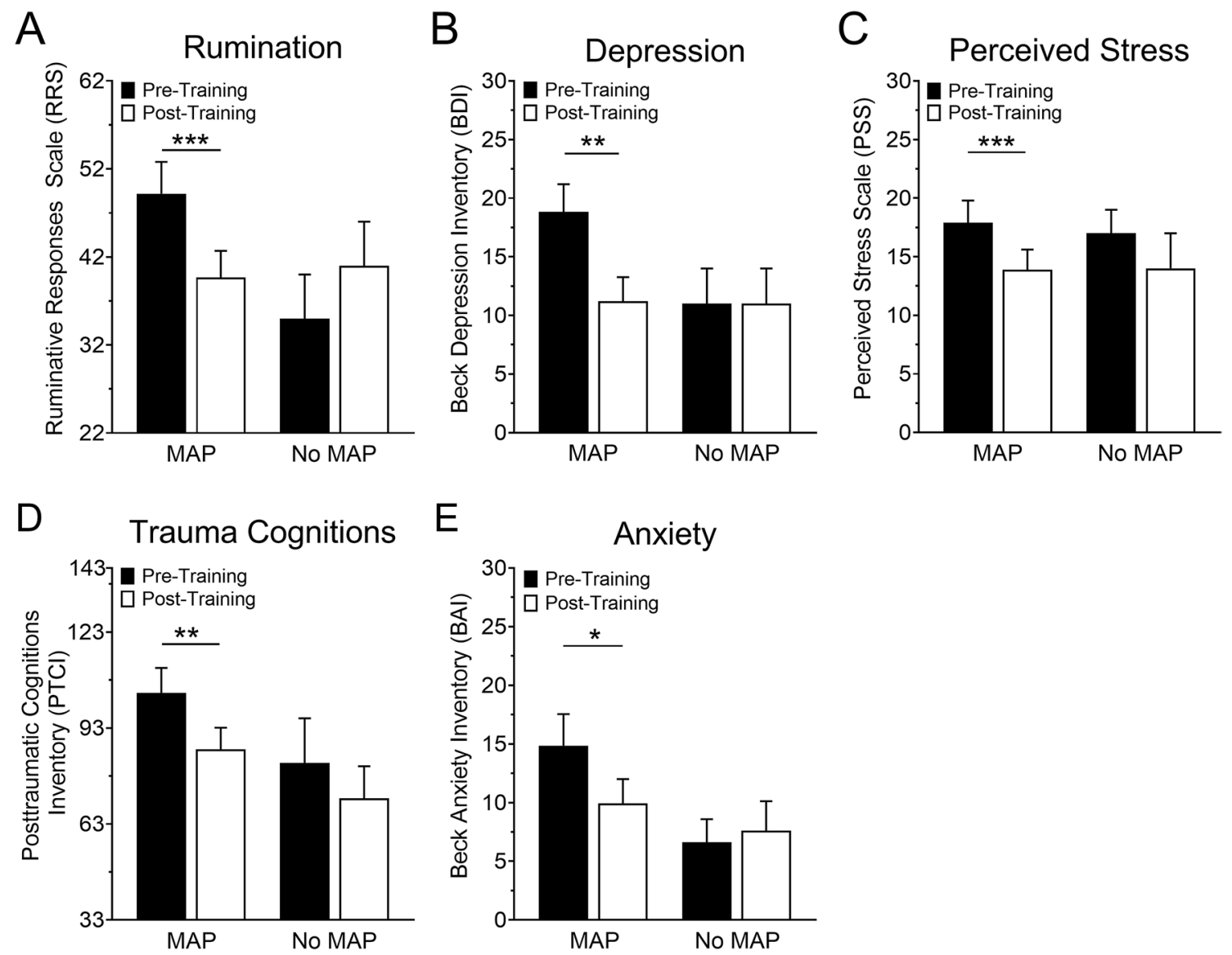

Fig. 1 Women with HIV reported significantly fewer $\mathbf{A}$ numbers of ruminative thoughts and $\mathbf{B}$ symptoms of depression compared to women who did not train with 6 weeks of combined meditation and aerobic exercise. Women who trained also reported significant reduc-

tions in $\mathbf{C}$ perceived stress, $\mathbf{D}$ trauma-related cognitions, and $\mathbf{E}$ anxiety symptoms, while responses in women who did not train did not change. $* p<0.05, * * p<0.01, * * * p<0.001$
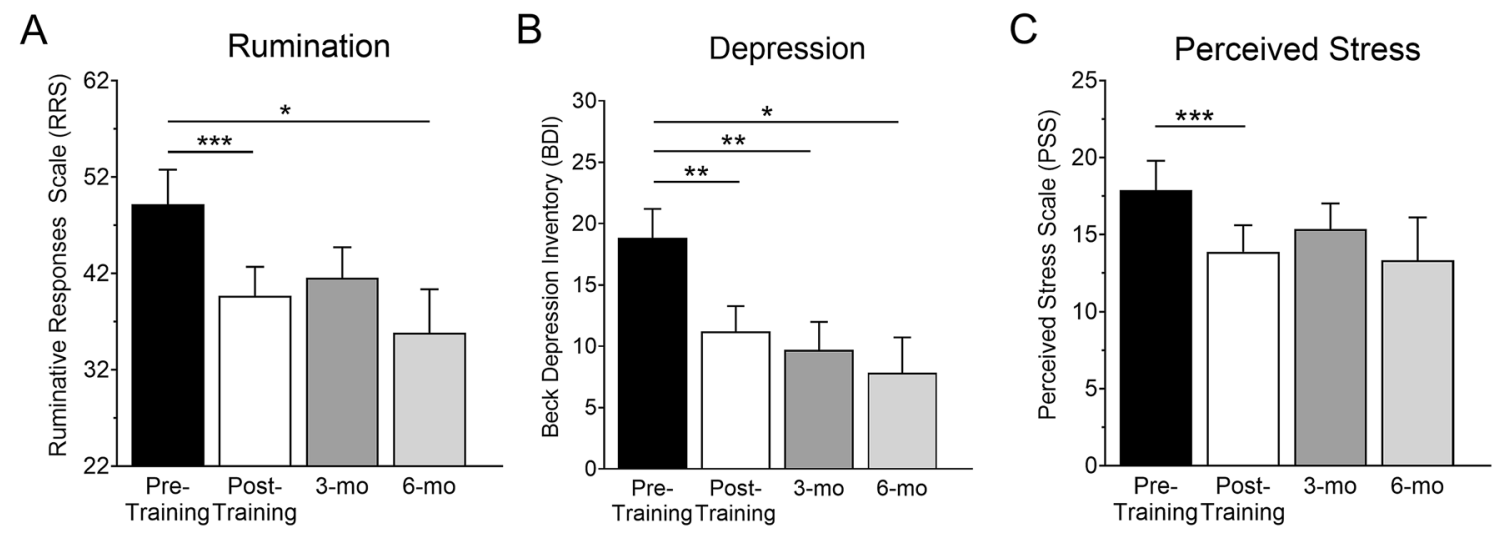

Fig. 2 A Decreases in rumination as assessed with the Ruminative Responses Scale persisted for 6 months but not 3 months. B Decreases in depressive symptoms as assessed with the Beck Depression Inventory persisted 3 months and 6 months after training. C
Decreases in perceived stress as assessed with the Perceived Stress Scale decreased after training but not 3 months and 6 months after training. $* p<0.05, * * p<0.01, * * * p<0.001$ 


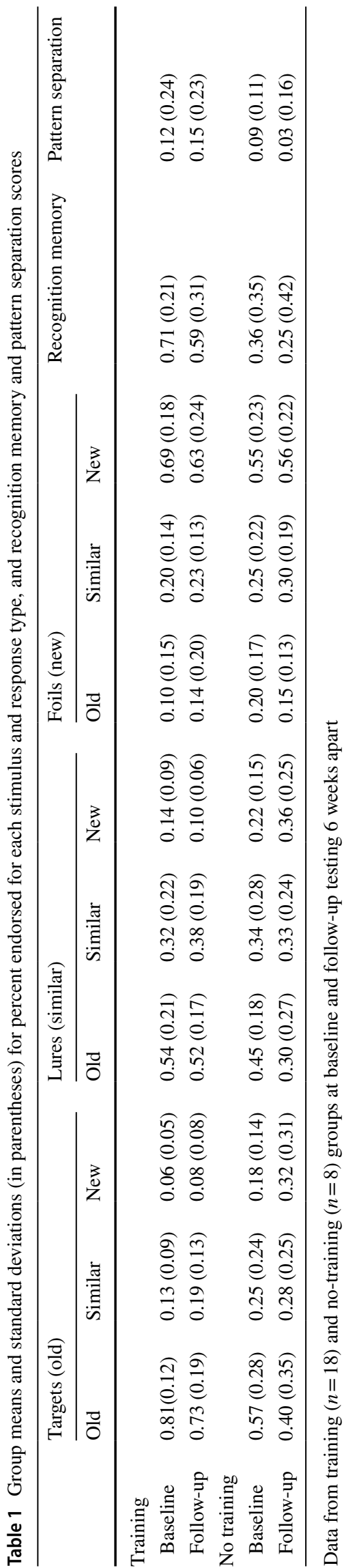

\section{Physiological Outcomes}

HRV measures were analyzed in women who engaged in 6 weeks of combined silent meditation and aerobic exercise training. None of the HRV measures changed significantly after training ( $p$ 's $>0.05)$. Group means, standard deviations, standard errors of means, and effect sizes of HRV outcomes are reported in Table 2. Total number of breaths counted during the 5-min rest period did not change as a result of training, $t(10)=-0.27, p>0.05$.

\section{Discussion}

Living with a chronic condition such as HIV impacts the brain and the body, contributing to disruptions in mental and physical health (Gore-Felton \& Koopman, 2008; Ivanova et al., 2012; Looby et al., 2018). Here we were interested in determining whether an intervention that targets both mental and physical health would benefit women living with HIV. The program, known as MAP Training and trademarked as MAP Train My Brain ${ }^{\mathrm{TM}}$ combines 30 min of mental training with meditation followed by $30 \mathrm{~min}$ of aerobic exercise. Similar interventions have proved appealing for people living with HIV. For example, a meta-analysis of physical exercise interventions for people with HIV report high adherence rates (e.g., 75\% or above; Dolan et al., 2006a, 2006b; O'Brien et al., 2016), although adherence for meditative practices were less robust (Ramirez-Garcia et al., 2019b). To date, most interventions for people with HIV have targeted men (Brown \& Vanable, 2008; Crepaz et al., 2014; Spaan et al., 2020). Given these limitations, we tested whether a relatively simple and cost-effective intervention that combines both mental and physical training would benefit women with HIV who were living in Newark, New Jersey and who frequented clinics in the area for their antiviral medication and clinical support. In this study, women who engaged in the program once a week for 6 weeks reported significantly fewer depressive and anxiety symptoms as well as significantly less perceived stress. They also reported fewer ruminative and traumatic thoughts after training. The effects on rumination and depression were long-lasting, persisting up to 6 months after the training. The only measure that did not persist over time was that of perceived stress, which reflects feelings of stress during recent and present day life. The majority of participants reported that they continued the program after the 6 weeks of training, supporting study feasibility. Thus, the intervention seems to induce relatively long-lasting effects in overall mental health with and without continued practice and with the exception of perceived stress, potentially as it is a measure of more recent and present day experience. 
Fig. 3 A Behavioral Pattern Separation Task adapted from Stark and colleagues (2013). Participants initially encoded a series of everyday objects. The encoding phase was immediately followed by a surprise recognition test that had 64 identical images to those from the encoding phase (old), 64 novel objects not previously seen, and 64 objects similar to what participants had seen before in the encoding phase but not exactly the same. B Women with HIV who engaged in 6 weeks of training significantly improved on pattern separation accuracy (assessed by the percentage of correct responses to similar items), while performance in women who did not train did not change $* p<0.05$. C Women with HIV with recognition memory scores of $80 \%$ or above prior to training $(n=8)$ were assessed on pattern separation scores (calculated as the percentage of correct responses to similar objects minus the percentage of incorrect similar responses to novel objects). Their performance improved after 6 weeks of combined meditation and aerobic exercise training $(p<0.05)$

\section{A Behavioral Pattern Separation Task}
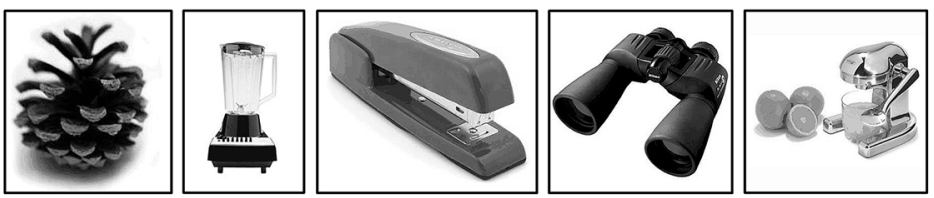

encoding phase: indoor or outdoor?

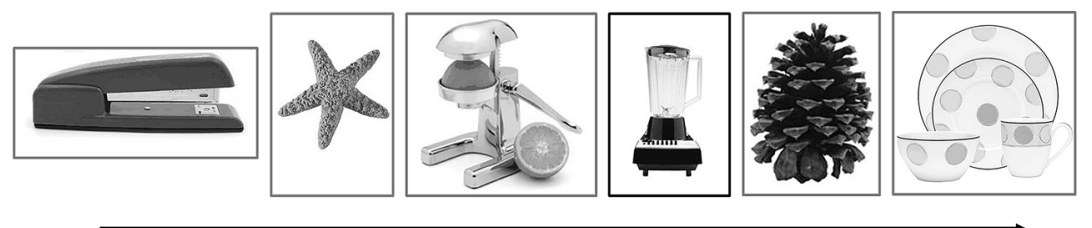

test phase: old, new, similar?
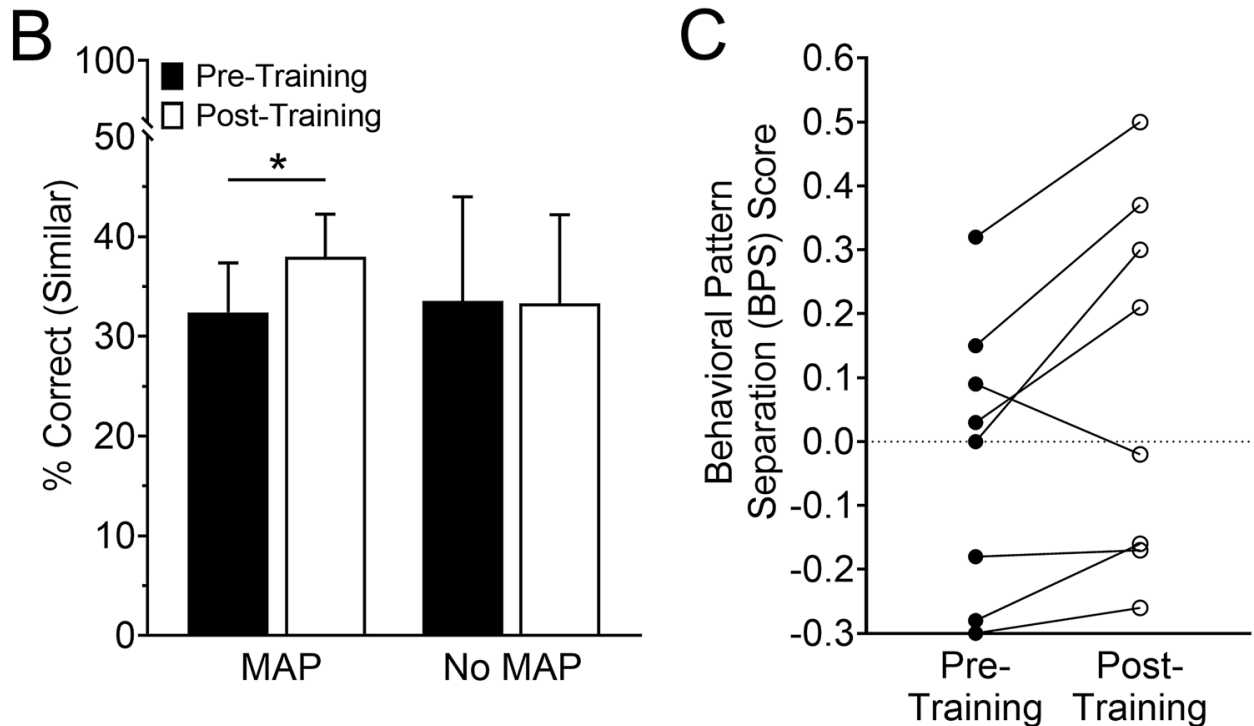

In a previous study with this population, women who reported a greater tendency to ruminate also reported higher levels of perceived stress, as well as greater numbers of anxiety and depressive symptoms, suggesting there is a relationship between these outcomes within individuals (Millon \& Shors, 2021). A factor analysis of these data identified a primary factor, which we termed "mental health" because it accounted for about $66 \%$ of the variance for all the mental health outcomes. This factor accounted for $94 \%$ of the variance in ruminative thoughts, as well as most of the variance in the measures of anxiety and depression reported by the individuals (Millon \& Shors, 2021). Thus, rumination emerged as an especially strong predictor of overall mental health and may be a target for improving other mental health symptoms related to stress and trauma, including those that emerge while living with HIV. In the present study, women with HIV did report a relatively high degree of ruminative thoughts that decreased by nearly $20 \%$ in those who completed the 6-week training program. This effect was significant and similar to other reports with differing populations engaging in the same training program (Alderman et al., 2016; Lavadera et al., 2020; Shors et al., 2018). Thus, targeting rumination may be a useful strategy for decreasing other measures of stress, including those related to depression and anxiety.

\section{MAP Training Enhanced Discrimination Learning/ Pattern Separation}

Pattern separation is a type of discrimination learning that is used to describe a computational process that transforms similar inputs into distinct, non-overlapping outputs (Marr, 
Table 2 Heart rate variability measures (log-transformed) prior to and after combined meditation and aerobic exercise training $(n=15)$

\begin{tabular}{|c|c|c|c|c|c|c|c|c|}
\hline & \multicolumn{3}{|c|}{ Pre-training } & \multicolumn{3}{|c|}{ Post-training } & \multirow[t]{2}{*}{$p$} & \multirow[t]{2}{*}{ Cohen's $d$} \\
\hline & Mean & SD & SEM & Mean & SD & SEM & & \\
\hline SDNN & 3.14 & 0.67 & 0.17 & 3.18 & 0.65 & 0.17 & $>0.05$ & 0.09 \\
\hline RMSSD & 3.16 & 0.79 & 0.20 & 3.19 & 0.78 & 0.20 & $>0.05$ & 0.06 \\
\hline VLF Power $\left(\mathrm{ms}^{2}\right)$ & 3.33 & 1.23 & 0.32 & 3.07 & 0.90 & 0.23 & $>0.05$ & 0.21 \\
\hline LF Power $\left(\mathrm{ms}^{2}\right)$ & 5.21 & 1.19 & 0.31 & 5.31 & 1.17 & 0.30 & $>0.05$ & 0.09 \\
\hline HF power $\left(\mathrm{ms}^{2}\right)$ & 5.40 & 1.55 & 0.40 & 5.27 & 1.53 & 0.40 & $>0.05$ & 0.13 \\
\hline $\mathrm{LF} / \mathrm{HF}$ ratio & -0.20 & 0.77 & 0.20 & 0.05 & 0.91 & 0.24 & $>0.05$ & 0.23 \\
\hline
\end{tabular}

1971; McClelland et al., 1995). This type of learning is often associated with the anatomy of the hippocampal formation and the presence of newly generated neurons in the dentate gyrus (e.g., Clelland et al., 2009; Drew et al., 2010; Snyder et al., 2005). To explore this relationship in humans, Stark and colleagues developed the Behavioral Pattern Separation Task, also known as the Mnemonic Similarity Task (Bakker et al., 2008; Clelland et al., 2009; Kirwan et al., 2012; Lacy et al., 2011; Stark et al., 2013). We used this task in the present study. Before and after the 6-week training program, participants were asked to detect differences in objects that were either the same or slightly different from objects they had viewed beforehand. The participants who completed the training and performed well on the recognition aspect of the task were better able to discriminate between very similar patterns of information (Fig. 3). It is not clear how such a change in learning would translate into the everyday lives of participants living with HIV. Most of the participants experienced past traumas and were currently experiencing traumarelated cognitions while living in an inner city environment. Thus, it is hypothesized that even a minor enhancement in this kind of skill learning may have some benefit, as people navigate in an environment within which they must distinguish between potentially dangerous contexts and those that are similar but safe (e.g., Jovanovic et al., 2012; Sangha et al., 2020; Thome et al., 2018).

As noted, learning to discriminate similar patterns of information is most often associated with the hippocampus, a part of the brain used for generating new memories (Bakker et al., 2008; Clelland et al., 2009; Kirwan et al., 2012; Lacy et al., 2011; Stark et al., 2013). But the mental and physical activities that were used in the MAP Training intervention likely activate multiple brain regions. For example, the practice of meditation alone engages a broad range of executive and/or cognitive control networks (e.g., dorsolateral prefrontal cortex, inferior frontal gyrus), as does aerobic exercise alone (Ji et al., 2017; Voss et al., 2010; Weng et al., 2017). In contrast, engaging in ruminative thinking reportedly decreases activity in similar regions, while increasing activity in regions involved in self-referential thinking, especially within the temporal lobe (Kaiser et al., 2019; Nejad et al., 2013, 2019; Zhou et al., 2020).
Perhaps the intervention preferentially engages networks engaged in cognitive control processes to reduce ruminative thinking and enhance aspects of cognition, including the improvement in pattern separation that we report here. For example, the medial temporal lobe was reportedly more active while people were engaging in the pattern separation task used in the present study (Nash et al., 2021). Although speculative at this point, interventions that enhance activity in medial temporal brain regions might be beneficial not only for discrimination learning but also for breaking away from cognitive processes involved in rumination.

To date, most intervention studies aimed at enhancing cognition in people with HIV have been conducted in men. For example, men with HIV who regularly exercised performed better on a motor speed task compared to men who did not exercise (Honn et al., 1999); similar effects were observed for working memory (Dufour et al., 2013). Men with HIV reported fewer cognitive problems after a randomized control trial of weekly aerobic and resistance training over 6 months (Fillipas et al., 2006). However, these effects may depend on the type of activity. One study reported no change in cognition after a yoga intervention, which was not aerobic (Quigley et al., 2020). Therefore, the increase in pattern separation in women with HIV reported here is novel. However, we had access to a relatively small group and after eliminating those who did not perform well on the basic memory skills, it was a smaller sample. Nonetheless, the changes were significant and perhaps meaningful for their ability to distinguish between similar patterns of information in their everyday lives.

\section{Heart Rate Variability Related to Aerobic Exercise and Meditation}

In contrast to the broad effect on mental health outcomes, there was no appreciable change in any measure related to HRV. Several outcomes were assessed including canonical time (e.g., SDNN, RMSSD) and frequency (e.g., low-frequency, high-frequency, low/high frequency ratio) measures. In general, these measures provide an estimate of the health of the ANS and its ability to respond adaptively to stressors in the environment. Changes in HRV following short-term 
physical training depend on a variety of factors, including the duration and type of training, as well as a person's baseline vagal and sympathethic activity prior to training (e.g., Grässler et al., 2021). A positive response to MAP Training, and in particular an increase in high-frequency HRV, might have indicated greater parasympathetic activation of the ANS, and potentially decreased risk for related physical health issues such as cardiovascular disease.

The absence of a meaningful change was somewhat surprising but not entirely unexpected. HRV is often used as an indicator of overall physical health because people who are more aerobically fit tend to have higher HRV (e.g., De Meersman, 1993), while those with heart disease and other risk factors have less (Kleiger et al., 1987; Tsuji et al., 1994; Vaishnav et al., 1994). Some studies suggest that mental health is also related to HRV, and those with depression exhibit reduced HRV (Sgoifo et al., 2015). Certainly, aerobic training can increase HRV (e.g., Reardon \& Malik, 1996). For example, post-menopausal women who regularly endurance trained (quantified as running an average of 32 miles per week) had greater HRV compared to women who did not regularly exercise (Davy et al., 1996). However, it is difficult to change HRV with one session a week for 6 weeks (Davy et al., 1996; Masroor et al., 2018). Most studies indicate that more sustained exercise is necessary to change HRV. For example, HRV increased with training five times a week for four weeks in sedentary middle-aged women (Masroor et al., 2018). Another study reported greater SDNN in people living with HIV following eight weeks of aerobic exercise, practiced three times a week (Quiles et al., 2020), but no difference in frequency-domain measures of HRV (Quiles et al., 2020). Another study assessed HRV prior to, during, and after 20 min of treadmill exercise (performed at $60 \%$ of maximum oxygen intake) (Borges et al., 2012). People with HIV had less SDNN and low- and high-frequency HRV at rest, as well as significantly less low- and high-frequency HRV compared to controls (Borges et al., 2012).

It is hard to compare our data to others who have assessed HRV in HIV populations because there are so few studies and most were conducted in men. The SDNN and low-frequency HRV measures reported in our study were lower than those reported by Borges and colleagues (2012); however,only three females participated. For the most part, men have higher HRV than women (e.g., Koenig \& Thayer, 2016) though age is also a factor (Stein et al., 1997). The SDNN values in our study were also lower than those reported by Quiles and colleagues (2020), both before and after their aerobic exercise intervention. Also, we did not measure HRV in people without HIV so we are not able to report on the impact of HIV itself on HRV; however, others have reported decreased low- and high-frequency HRV in people with AIDS (Neild et al., 2000). With respect to meditation, effects on HRV are even less consistent (Amihai \&
Kozhevnikov, 2014; Cysarz \& Büssing, 2005; Lehrer et al., 1999; Léonard et al., 2019). In summary, 6 weeks of MAP Training were not sufficient to alter persistently common measures of HRV and thus are unlikely to account for the improvement in mental health outcomes that were observed here and in our other studies (Alderman et al., 2016; Lavadera et al., 2020; Shors et al., 2014, 2018).

\section{Feasibility and Limitations}

This pilot study demonstrated that 6 weeks of combined meditation and aerobic exercise is beneficial for women living with a chronic virus in an urban city, many of whom were suffering from a variety of mental and physical health challenges. Yet, there were several limitations to the study. First, we did not test participants without HIV and therefore, cannot compare our results to those in people without HIV. In addition, the study was not a randomized control trial and sample sizes were unequal. We did retain $~ 75 \%$ of the sample throughout the study, which is a higher rate than reported in prior studies with this intervention (Alderman et al., 2016; Shors et al., 2018). Although most outcome measures did not differ between groups prior to training, the women who volunteered for the training did report more ruminative thoughts, which might have accounted for their willingness to participate in training. In addition, we did not assess other measures of cognition, in part because of time limitations. There was no change in novelty detection or recognition memory as a result of training. Finally, we did not collect data on viral load or CD4 cell counts, and therefore are not able to determine whether training improved physical health indicators of HIV status.

\section{Conclusion}

Overall, a combination of mental and physical exercise, known as MAP Training, appears to be an effective therapy for women who live each day with a chronic disease that impacts the health of their brain and body. In particular, this pilot study demonstrated that an intervention that targets mental and physical health is feasible for a female HIV population suffering from multiple stressors to their physical and mental health and living with few socioeconomic resources. Mental health outcomes, including ruminative and traumarelated thoughts, as well as symptoms of depression, anxiety, and perceived stress, were significantly reduced after 6 weeks of training with meditation and aerobic exercise. HRV did not change after training, but learning to discriminate very similar patterns of information was enhanced. The MAP Training program is relatively easy to implement and it does not depend on extraordinary finances or specialized 
equipment. Based on the pilot data presented here, it may be a manageable fitness program for people who are living with a chronic illness and have limited resources for maintaining everyday health and wellness.

Acknowledgements The authors would like to thank the late Dr. Evgeny Vaschillo for his guidance with data analysis, as well as Peter Bartalis, Sarah Abdelaal and Esther Bennett for their assistance with data collection.

Funding This research did not receive funding support.

\section{Declarations}

Conflict of interest The authors declare that they have no conflict of interest.

\section{References}

Adimora, A. A., \& Schoenbach, V. J. (2005). Social context, sexual networks, and racial disparities in rates of sexually transmitted infections. Journal of Infectious Diseases, 191, S115-S122.

Akselrod, S., Gordon, D., Ubel, F. A., Shannon, D. C., Berger, A. C., \& Cohen, R. J. (1981). Power spectrum analysis of heart rate fluctuation: A quantitative probe of beat-to-beat cardiovascular control. Science, 213(4504), 220-222. https://doi.org/10.1126/ science. 6166045

Alderman, B. L., Olson, R. L., Brush, C. J., \& Shors, T. J. (2016). Mental and physical (MAP) training: Combining meditation and aerobic exercise reduces depression and rumination while enhancing synchronized brain activity. Translational Psychiatry, 6, e726.

Amihai, I., \& Kozhevnikov, M. (2014). Arousal vs. relaxation: A comparison of the neurophysiological and cognitive correlates of vajrayana and theravada meditative practices. PLOS ONE, 9(7), e102990. https://doi.org/10.1371/journal.pone.0102990

Asahchop, E. L., Meziane, O., Mamik, M. K., Chan, W. F., Branton, W. G., Resch, L., Gill, M. J., Haddad, E., Guimond, J. V., Wainberg, M. A., Baker, G. B., Cohen, E. A., \& Power, C. (2017). Reduced antiretroviral drug efficacy and concentration in HIV-infected microglia contributes to viral persistence in brain. Retrovirology, 14(1), 47. https://doi.org/10.1186/s12977-017-0370-5

Bakker, A., Kirwan, C. B., Miller, M., \& Stark, C. E. L. (2008). Pattern separation in the human hippocampal CA3 and dentate gyrus. Science, 319(5870), 1640-1642. https://doi.org/10.1126/scien ce. 1152882

Beck, A., Epstein, N., Brown, G., \& Steer, R. (1988). An inventory for measuring clinical anxiety: Psychometric properties. Journal of Consulting and Clinical Psychology, 56(6), 893-897.

Beck, A., Steer, R., \& Brown, G. (1996). Manual for the Beck depression inventory-II. Psychological Corporation.

Beer, L., Tie, Y., Padilla, M., Shouse, R. L., Medical Monitoring Project. (2019). Generalized anxiety disorder symptoms among persons with diagnosed HIV in the United States. AIDS, 33(11), $1781-1787$

Billman, G. E. (2013). The LF/HF ratio does not accurately measure cardiac sympatho-vagal balance. Frontiers in Physiology, 4, 26. https://doi.org/10.3389/fphys.2013.00026

Bird, S. T., \& Bogart, L. M. (2001). Perceived race-based and socioeconomic status(SES)-based discrimination in interactions with health care providers. Ethnicity \& Disease, 11(3), 554-563.
Borges, J., Soares, P., \& Farinatti, P. (2012). Autonomic modulation following exercise is impaired in HIV patients. International Journal of Sports Medicine, 33(4), 320-324. https://doi.org/10. 1055/s-0031-1297954

Brown, J. L., \& Vanable, P. A. (2008). Cognitive-behavioral stress management interventions for persons living with HIV: A review and critique of the literature. Annals of Behavioral Medicine, 35(1), 26-40. https://doi.org/10.1007/s12160-007-9010-y

Centers for Disease Control and Prevention (CDC). (2011). Characteristics associated with HIV infection among heterosexuals in urban areas with high AIDS prevalence-24 cities, United States, 2006-2007. MMWR, 60(31), 1045-1049.

Clelland, C. D., Choi, M., Romberg, C., Clemenson, G. D., Fragniere, A., Tyers, P., Jessberger, S., Saksida, L. M., Barker, R. A., Gage, F. H., \& Bussey, T. J. (2009). A functional role for adult hippocampal neurogenesis in spatial pattern separation. Science, 325(5937), 210-213. https://doi.org/10.1126/science.1173215

Cohen, S., Kamarck, T., \& Mermelstein, R. (1983). A global measure of perceived stress. Journal of Health and Social Behavior, 24, 386-396.

Crepaz, N., Tungol-Ashmon, M. V., Higa, D. H., Vosburgh, W., Mullins, M. M., Barham, T., Adegbite, A., DeLuca, J. B., Sipe, T. A., White, C. M., Baack, B. N., \& Lyles, C. M. (2014). A systematic review of interventions for reducing HIV risk behaviors among people living with HIV in the United States, 1988-2012. AIDS, 28(5), 633-656.

Cysarz, D., \& Büssing, A. (2005). Cardiorespiratory synchronization during Zen meditation. European Journal of Applied Physiology, 95(1), 88-95. https://doi.org/10.1007/s00421-005-1379-3

Davy, K. P., Miniclier, N. L., Taylor, J. A., Stevenson, E. T., \& Seals, D. R. (1996). Elevated heart rate variability in physically active postmenopausal women: A cardioprotective effect? The American Journal of Physiology, 271(2), H455-H460. https://doi.org/ 10.1152/ajpheart.1996.271.2.H455

De Meersman, R. E. (1993). Heart rate variability and aerobic fitness. American Heart Journal, 125(3), 726-731. https://doi.org/10. 1016/0002-8703(93)90164-5

Demmin, D. L., Silverstein, S., Shors, T. J. (2021). Mental and Physical (MAP) Training with meditation and aerobic exercise during the COVID-19 pandemic reduces stress and improves well-being in teachers, submitted, 2021

Dolan, S. E., Frontera, W., Librizzi, J., Ljungquist, K., Juan, S., Dorman, R., Cole, M. E., Kanter, J. R., \& Grinspoon, S. (2006a). Effects of a supervised home-based aerobic and progressive resistance training regimen in women infected with human immunodeficiency virus: A randomized trial. Archives of Internal Medicine, 166(11), 1225-1231.

Dolan, S. E., Frontera, W., Librizzi, J., Ljungquist, K., Juan, S., Dorman, R., Cole, M. E., Kanter, J. R., \& Grinspoon, S. (2006b). Effects of a supervised home-based aerobic and progressive resistance training regimen in women infected with human immunodeficiency virus. Archives of Internal Medicine, 166(11), 1225-1231. https://doi.org/10.1001/archinte.166.11.1225

Drew, M. R., Denny, C. A., \& Hen, R. (2010). Arrest of adult hippocampal neurogenesis in mice impairs single- but not multiple-trial contextual fear conditioning. Behavioral Neuroscience, 124(4), 446-454. https://doi.org/10.1037/a0020081

Dufour, C. A., Marquine, M. J., Fazeli, P. L., Henry, B. L., Ellis, R. J., Grant, I., \& Moore, D. J. (2013). Physical exercise is associated with less neurocognitive impairment among HIV-infected adults. Journal of Neurovirology, 19(5), 410-417. https://doi.org/ 10.1007/s13365-013-0184-8

Fillipas, S., Oldmeadow, L. B., Bailey, M. J., \& Cherry, C. L. (2006). A six-month, supervised, aerobic and resistance exercise program improves self-efficacy in people with human immunodeficiency virus: A randomised controlled trial. The Australian Journal of 
Physiotherapy, 52(3), 185-190. https://doi.org/10.1016/s00049514(06)70027-7

Fisher, S. D., Easley, K. A., Orav, E. J., Colan, S. D., Kaplan, S., Starc, T. J., Bricker, J. T., Lai, W. W., Moodie, D. S., Sopko, G., \& Lipshultz, S. E. (2005). Mild dilated cardiomyopathy and increased left ventricular mass predict mortality: The prospective P2C2 HIV multicenter study. American Heart Journal, 150(3), 439447. https://doi.org/10.1016/j.ahj.2005.06.012

Foa, E. B., Ehlers, A., Clark, D. M., Tolin, D. F., \& Orsillo, S. M. (1999). The posttraumatic cognitions inventory (PTCI): Development and validation. Psychological Assessment, 11(3), 303-314. https://doi.org/10.1037/1040-3590.11.3.303

Foa, E. B., \& Rauch, S. A. M. (2004). Cognitive changes during prolonged exposure versus prolonged exposure plus cognitive restructuring in female assault survivors with posttraumatic stress disorder. Journal of Consulting and Clinical Psychology, 72(5), 879-884. https://doi.org/10.1037/0022-006X.72.5.879

$\mathrm{Fu}$, Q., \& Levine, B. D. (2013). Exercise and the autonomic nervous system. Handbook of Clinical Neurology, 117, 147-160. https:// doi.org/10.1016/B978-0-444-53491-0.00013-4

Gerlach, D. A., Manuel, J., Hoff, A., Kronsbein, H., Hoffmann, F., Heusser, K., Ehmke, H., Diedrich, A., Jordan, J., Tank, J., \& Beissner, F. (2019). Novel approach to elucidate human baroreflex regulation at the brainstem level: Pharmacological testing during fMRI. Frontiers in Neuroscience, 13, 193. https://doi.org/ 10.3389/fnins.2019.00193

Goldstein, D. S., Bentho, O., Park, M.-Y., \& Sharabi, Y. (2011). Lowfrequency power of heart rate variability is not a measure of cardiac sympathetic tone but may be a measure of modulation of cardiac autonomic outflows by baroreflexes. Experimental Physiology, 96(12), 1255-1261. https://doi.org/10.1113/expph ysiol.2010.056259

Gore-Felton, C., \& Koopman, C. (2008). Behavioral mediation of the relationship between psychosocial factors and HIV disease progression. Psychosomatic Medicine, 70(5), 569-574. https://doi. org/10.1097/PSY.0b013e318177353e

Gould, E., Beylin, A., Tanapat, P., Reeves, A., \& Shors, T. J. (1999). Learning enhances adult neurogenesis in the hippocampal formation. Nature Neuroscience, 2(3), 260-265. https://doi.org/10. 1038/6365

Grässler, B., Thielmann, B., Böckelmann, I., \& Hökelmann, A. (2021). Effects of different training interventions on heart rate variability and cardiovascular health and risk factors in young and middle-aged adults: A systematic review. Frontiers in Physiology. https://doi.org/10.3389/fphys.2021.657274

Honn, V. J., Para, M. F., Whitacre, C. C., \& Bornstein, R. A. (1999). Effect of exercise on neuropsychological performance in asymptomatic HIV infection. AIDS and Behavior, 3(1), 67-74. https://doi.org/10.1023/A:1025471503738

Hou, J., Fu, J., Meng, S., Jiang, T., Guo, C., Wu, H., Su, B., \& Zhang, T. (2020). Posttraumatic stress disorder and nonadherence to treatment in people living with HIV: A systematic review and meta-analysis. Frontiers in Psychiatry. https://doi.org/10.3389/ fpsyt.2020.00834

Hutton, H. E., Cardin, N., Ereme, K., Chander, G., Xu, X., \& McCaul, M. E. (2020). Psychiatric disorders and substance use among african american women in HIV care. AIDS and Behavior, 24(11), 3083-3092. https://doi.org/10.1007/ s10461-020-02858-6

IBM. (2019). IBM SPSS statistics for Mac (26.0) [Computer software]. IBM Corporation.

Ivanova, E. L., Hart, T. A., Wagner, A. C., Aljassem, K., \& Loutfy, M. R. (2012). Correlates of anxiety in women living with HIV of reproductive age. AIDS and Behavior, 16(8), 2181-2191. https:// doi.org/10.1007/s10461-011-0133-6
Ji, L., Zhang, H., Potter, G. G., Zang, Y.-F., Steffens, D. C., Guo, H., \& Wang, L. (2017). Multiple neuroimaging measures for examining exercise-induced neuroplasticity in older adults: A quasi-experimental study. Frontiers in Aging Neuroscience, 9, 102. https:// doi.org/10.3389/fnagi.2017.00102

Joseph, C. N., Porta, C., Casucci, G., Casiraghi, N., Maffeis, M., Rossi, M., \& Bernardi, L. (2005). Slow breathing improves arterial baroreflex sensitivity and decreases blood pressure in essential hypertension. Hypertension, 46(4), 714-718. https://doi.org/10. 1161/01.HYP.0000179581.68566.7d

Jovanovic, T., Kazama, A., Bachevalier, J., \& Davis, M. (2012). Impaired safety signal learning may be a biomarker of PTSD. Neuropharmacology, 62(2), 695-704. https://doi.org/10.1016/j. neuropharm.2011.02.023

Kaiser, R. H., Kang, M. S., Lew, Y., Van Der Feen, J., Aguirre, B., Clegg, R., Goer, F., Esposito, E., Auerbach, R. P., Hutchison, R. M., \& Pizzagalli, D. A. (2019). Abnormal frontoinsular-default network dynamics in adolescent depression and rumination: A preliminary resting-state co-activation pattern analysis. $\mathrm{Neu}$ ropsychopharmacology, 44, 1604-1612. https://doi.org/10.1038/ s41386-019-0399-3

Katz, S., \& Nevid, J. S. (2005). Risk factors associated with posttraumatic stress disorder symptomatology in HIV-infected women. AIDS Patient Care and STDs, 19, 110-120.

Kaufmann, T., Sütterlin, S., Schulz, S. M., \& Vögele, C. (2011). ARTiiFACT: A tool for heart rate artifact processing and heart rate variability analysis. Behavior Research Methods, 43(4), 1161-1170. https://doi.org/10.3758/s13428-011-0107-7

Kaul, M., Garden, G. A., \& Lipton, S. A. (2001). Pathways to neuronal injury and apoptosis in HIV-associated dementia. Nature, 410, 988-994.

Kirwan, C. B., Hartshorn, A., Stark, S. M., Goodrich-Hunsaker, N. J., Hopkins, R. O., \& Stark, C. E. L. (2012). Pattern separation deficits following damage to the hippocampus. Neuropsychologia, 50(10), 2408-2414. https://doi.org/10.1016/j.neuropsychologia. 2012.06.011

Kleiger, R. E., Miller, J. P., Bigger, J. T., \& Moss, A. J. (1987). Decreased heart rate variability and its association with increased mortality after acute myocardial infarction. The American Journal of Cardiology, 59(4), 256-262. https://doi.org/10.1016/00029149(87)90795-8

Koenig, J., \& Thayer, J. F. (2016). Sex differences in healthy human heart rate variability: A meta-analysis. Neuroscience and Biobehavioral Reviews, 64, 288-310. https://doi.org/10.1016/j.neubi orev.2016.03.007

Kovalevich, J., \& Langford, D. (2012). Neuronal toxicity in HIV CNS disease. Future Virology, 7(7), 687-698. https://doi.org/10.2217/ fvl.12.57

Lacy, J. W., Yassa, M. A., Stark, S. M., Muftuler, L. T., \& Stark, C. E. L. (2011). Distinct pattern separation related transfer functions in human CA3/dentate and CA1 revealed using high-resolution fMRI and variable mnemonic similarity. Learning \& Memory, 18(1), 15-18.

Lavadera, P., Millon, E. M., \& Shors, T. J. (2020). MAP Train My Brain $^{\mathrm{TM}}$ : Meditation combined with aerobic exercise reduces stress and rumination while enhancing quality of life in medical students. Journal of Alternative and Complementary Medicine, 26(5), 418-423. https://doi.org/10.1089/acm.2019.0281

Lehrer, P., \& Eddie, D. (2013). Dynamic processes in regulation and some implications for biofeedback and biobehavioral interventions. Applied Psychophysiology and Biofeedback, 38(2), 143155. https://doi.org/10.1007/s10484-013-9217-6

Lehrer, P., Sasaki, Y., \& Saito, Y. (1999). Zazen and cardiac variability. Psychosomatic Medicine, 61(6), 812-821. https://doi.org/10. 1097/00006842-199911000-00014 
Léonard, A., Clément, S., Kuo, C.-D., \& Manto, M. (2019). Changes in heart rate variability during heartfulness meditation: A power spectral analysis including the residual spectrum. Frontiers in Cardiovascular Medicine, 6, 62. https://doi.org/10.3389/fcvm. 2019.00062

Looby, S. E., Psaros, C., Raggio, G., Rivard, C., Smeaton, L., Shifren, J., Grinspoon, S., \& Joffe, H. (2018). Association between HIV status and psychological symptoms in perimenopausal women. Menopause, 25(6), 648-656. https://doi.org/10.1097/GME. 0000000000001058

Machtinger, E. L., Wilson, T. C., Haberer, J. E., \& Weiss, D. S. (2012). Psychological trauma and PTSD in HIV-positive women: A meta-analysis. AIDS and Behavior, 16(8), 2091-2100. https:// doi.org/10.1007/s10461-011-0127-4

Marr, D. (1971). Simple memory: A theory for archicortex. Philosophical Transactions of the Royal Society B, 262(841), 23-81. https:// doi.org/10.1098/rstb.1971.0078

Masroor, S., Bhati, P., Verma, S., Khan, M., \& Hussain, M. E. (2018). Heart rate variability following combined aerobic and resistance training in sedentary hypertensive women: A randomised control trial. Indian Heart Journal, 70(Suppl 3), S28-S35. https://doi. org/10.1016/j.ihj.2018.03.005

McClelland, J. L., McNaughton, B. L., \& O’Reilly, R. C. (1995). Why there are complementary learning systems in the hippocampus and neocortex: Insights from the successes and failures of connectionist models of learning and memory. Psychological Review, 102(3), 419-457.

Millon, E. M., Chang, H. Y. M., \& Shors, T. J. (2018). Stressful life memories relate to ruminative thoughts in women with sexual violence history, irrespective of PTSD. Frontiers in Psychiatry. https://doi.org/10.3389/fpsyt.2018.00311

Millon, E. M., \& Shors, T. J. (2019). Taking neurogenesis out of the lab and into the world with MAP Train My Brain ${ }^{\mathrm{TM}}$. Behavioural Brain Research, 376, 112154. https://doi.org/10.1016/j.bbr.2019. 112154

Millon, E. M., \& Shors, T. J. (2021). How mental health relates to everyday stress, rumination, trauma and interoception in women living with HIV: A factor analytic study. Learning and Motivation, 73, 101680. https://doi.org/10.1016/j.lmot.2020.101680

Mondy, K. E., Gottdiener, J., Overton, E. T., Henry, K., Bush, T., Conley, L., Hammer, J., Carpenter, C. C., Kojic, E., Patel, P., Brooks, J. T., SUN Study Investigators. (2011). High prevalence of echocardiographic abnormalities among HIV-infected persons in the era of highly active antiretroviral therapy. Clinical Infectious Diseases, 52(3), 378-386. https://doi.org/10.1093/cid/ciq066

Morrison, M. F., Petitto, J. M., Ten Have, T., Gettes, D. R., Chiappini, M. S., Weber, A. L., Brinker-Spence, P., Bauer, R. M., Douglas, S. D., \& Evans, D. L. (2002). Depressive and anxiety disorders in women with HIV infection. The American Journal of Psychiatry, 159(5), 789-796. https://doi.org/10.1176/appi.ajp.159.5.789

Nash, M. I., Hodges, C. B., Muncy, N. M., \& Kirwan, C. B. (2021). Pattern separation beyond the hippocampus: A high-resolution whole-brain investigation of mnemonic discrimination in healthy adults. Hippocampus, 31, 408-421.

Nejad, A. B., Fossati, P., \& Lemogne, C. (2013). Self-referential processing, rumination, and cortical midline structures in major depression. Frontiers in Human Neuroscience. https://doi.org/ 10.3389/fnhum.2013.00666

Nejad, A. B., Rotgé, J. Y., Valabregue, R., Guérin-Langlois, C., Hoertel, N., Gorwood, P., Dubertret, C., Limosin, F., Fossati, P., \& Lemogne, C. (2019). Medial prefrontal disengagement during self-focus in formerly depressed patients prone to rumination. Journal of Affective Disorders, 247, 36-44. https://doi.org/10. 1016/j.jad.2019.01.004
Neild, P. J., Amadi, A., Ponikowski, P., Coats, A. J., \& Gazzard, B. G. (2000). Cardiac autonomic dysfunction in AIDS is not secondary to heart failure. International Journal of Cardiology, 74(2-3), 133-137. https://doi.org/10.1016/s0167-5273(00)00232-1

Nightingale, V. R., Sher, T. G., \& Hansen, N. B. (2010). The impact of receiving an HIV diagnosis and cognitive processing on psychological distress and posttraumatic growth. Journal of Traumatic Stress, 23(4), 452-460. https://doi.org/10.1002/jts.20554

Nolen-Hoeksema, S., Larson, J., \& Grayson, C. (1999). Explaining the gender difference in depressive symptoms. Journal of Personality and Social Psychology, 77(5), 1061-1072.

O’Brien, K. K., Tynan, A.-M., Nixon, S. A., \& Glazier, R. H. (2016). Effectiveness of aerobic exercise for adults living with HIV: Systematic review and meta-analysis using the cochrane collaboration protocol. BMC Infectious Diseases. https://doi.org/10.1186/ s12879-016-1478-2

Orza, L., Bewley, S., Logie, C. H., Crone, E. T., Moroz, S., Strachan, S., Vazquez, M., \& Welbourn, A. (2015). How does living with HIV impact on women's mental health? Voices from a global survey. Journal of the International AIDS Society, 18, 20289. https://doi.org/10.7448/IAS.18.6.20289

Pagani, M., Lombardi, F., Guzzetti, S., Rimoldi, O., Furlan, R., Pizzinelli, P., Sandrone, G., Malfatto, G., Dell'Orto, S., \& Piccaluga, E. (1986). Power spectral analysis of heart rate and arterial pressure variabilities as a marker of sympatho-vagal interaction in man and conscious dog. Circulation Research, 59(2), 178-193. https://doi.org/10.1161/01.res.59.2.178

Pagani, M., Lombardi, F., Guzzetti, S., Sandrone, G., Rimoldi, O., Malfatto, G., Cerutti, S., \& Malliani, A. (1984). Power spectral density of heart rate variability as an index of sympatho-vagal interaction in normal and hypertensive subjects. Journal of Hypertension. Supplement, 2(3), S383-S385.

Pellowski, J. A., Kalichman, S. C., Matthews, K. A., \& Adler, N. (2013). A pandemic of the poor: Social disadvantage and the U.S. HIV epidemic. The American Psychologist, 68(4), 197-209. https://doi.org/10.1037/a0032694

Quigley, A., Brouillette, M.-J., Gahagan, J., O’Brien, K. K., \& MacKay-Lyons, M. (2020). Feasibility and impact of a yoga intervention on cognition, physical function, physical activity, and affective outcomes among people living with HIV: A randomized controlled pilot trial. Journal of the International Association of Providers of AIDS Care, 19, 2325958220935698. https://doi.org/ $10.1177 / 2325958220935698$

Quiles, N., Taylor, B., \& Ortiz, A. (2020). Effectiveness of an 8-Week Aerobic Exercise Program on Autonomic Function in People Living with HIV Taking Anti-Retroviral Therapy: A Pilot Randomized Controlled Trial. AIDS Research and Human Retroviruses, 36(4), 283-290. https://doi.org/10.1089/AID.2019.0194

Ramirez-Garcia, M. P., Gagnon, M. P., Colson, S., Côté, J., FloresAranda, J., \& Dupont, M. (2019a). Mind-body practices for people living with HIV: A systematic scoping review. BMC Complementary and Alternative Medicine. https://doi.org/10.1186/ s12906-019-2502-Z

Ramirez-Garcia, M. P., Gagnon, M.-P., Colson, S., Côté, J., FloresAranda, J., \& Dupont, M. (2019b). Mind-body practices for people living with HIV: A systematic scoping review. BMC Complementary and Alternative Medicine, 19(1), 125. https://doi.org/10. 1186/s12906-019-2502-z

Reardon, M., \& Malik, M. (1996). Changes in heart rate variability with age. Pacing and Clinical Electrophysiology, 19(11), 18631866. https://doi.org/10.1111/j.1540-8159.1996.tb03241.x

Reyes del Paso, G. A., Langewitz, W., Mulder, L. J. M., van Roon, A., \& Duschek, S. (2013). The utility of low frequency heart rate variability as an index of sympathetic cardiac tone: A review 
with emphasis on a reanalysis of previous studies. Psychophysiology, 50(5), 477-487. https://doi.org/10.1111/psyp.12027

Rogstad, K. E., Shah, R., Tesfaladet, G., Abdullah, M., \& AhmedJushuf, I. (1999). Cardiovascular autonomic neuropathy in HIV infected patients. Sexually Transmitted Infections, 75(4), 264 267. https://doi.org/10.1136/sti.75.4.264

Sangha, S., Diehl, M. M., Bergstrom, H. C., \& Drew, M. R. (2020). Know safety, no fear. Neuroscience and Biobehavioral Reviews, 108, 218-230. https://doi.org/10.1016/j.neubiorev.2019.11.006

Sayers, B. M. (1973). Analysis of heart rate variability. Ergonomics, 16(1), 17-32. https://doi.org/10.1080/00140137308924479

Schulte, M. T., Marelich, W. D., Payne, D. L., Tarantino, N., Armistead, L. P., \& Murphy, D. A. (2018). Validation of a brief measure of HIV health-related anxiety among women living with HIV. Research in Nursing \& Health, 41(4), 398-407. https://doi.org/ 10.1002/nur.21876

Schumann, A., de la Cruz, F., Köhler, S., Brotte, L., \& Bär, K.-J. (2021). The influence of heart rate variability biofeedback on cardiac regulation and functional brain connectivity. Frontiers in Neuroscience, 15, 775. https://doi.org/10.3389/fnins.2021. 691988

Sgoifo, A., Carnevali, L., Alfonso, M. A. P., \& Amore, M. (2015). Autonomic dysfunction and heart rate variability in depression. Stress, 18(3), 343-352. https://doi.org/10.3109/10253890.2015. 1045868

Shaffer, F., \& Ginsberg, J. P. (2017). An overview of heart rate variability metrics and norms. Frontiers in Public Health. https://doi. org/10.3389/fpubh.2017.00258

Shors, T. J., Chang, H. Y. M., \& Millon, E. M. (2018). MAP Training My Brain ${ }^{\mathrm{TM}}$ : Meditation plus aerobic exercise lessens trauma of sexual violence more than either activity alone. Frontiers in Neuroscience. https://doi.org/10.3389/fnins.2018.00211

Shors, T. J., \& Millon, E. M. (2016). Sexual trauma and the female brain. Frontiers in Neuroendocrinology. https://doi.org/10. 1016/j.yfrne.2016.04.001

Shors, T. J., Millon, E. M., Chang, H. Y. M., Olson, R. L., \& Alderman, B. L. (2017). Do sex differences in rumination explain sex differences in depression? Journal of Neuroscience Research, 95(1-2), 711-718. https://doi.org/10.1002/jnr.23976

Shors, T. J., Olson, R. L., Bates, M. E., Selby, E. A., \& Alderman, B. L. (2014). Mental and physical (MAP) training: A neurogenesisinspired intervention that enhances health in humans. In Neurobiology of Learning and Memory. https://doi.org/10.1016/j. nlm.2014.08.012

Snyder, J. S., Hong, N. S., McDonald, R. J., \& Wojtowicz, J. M. (2005). A role for adult neurogenesis in spatial long-term memory. Neuroscience, 130(4), 843-852. https://doi.org/10.1016/j.neuroscien ce.2004.10.009

Spaan, P., van Luenen, S., Garnefski, N., \& Kraaij, V. (2020). Psychosocial interventions enhance HIV medication adherence: A systematic review and meta-analysis. Journal of Health Psychology, 25(10-11), 1326-1340. https://doi.org/10.1177/1359105318 755545

Spierer, D. K., DeMeersman, R. E., Kleinfeld, J., McPherson, E., Fullilove, R. E., Alba, A., \& Zion, A. S. (2007). Exercise training improves cardiovascular and autonomic profiles in HIV. Clinical Autonomic Research, 17(6), 341-348. https://doi.org/10.1007/ s10286-007-0441-0

Spies, G., Asmal, L., \& Seedat, S. (2013). Cognitive-behavioural interventions for mood and anxiety disorders in HIV: A systematic review. Journal of Affective Disorders, 150(2), 171-180. https:// doi.org/10.1016/j.jad.2013.04.018

Stark, S. M., Yassa, M. A., Lacy, J. W., \& Stark, C. E. L. (2013). A task to assess behavioral pattern separation (BPS) in humans: Data from healthy aging and mild cognitive impairment.
Neuropsychologia, 51(12), 2442-2449. https://doi.org/10.1016/j. neuropsychologia.2012.12.014

Stein, P. K., \& Kleiger, R. E. (1999). Insights from the study of heart rate variability. Annual Review of Medicine, 50, 249-261.

Tarvainen, M. P., Niskanen, J.-P., Lipponen, J. A., Ranta-Aho, P. O., \& Karjalainen, P. A. (2014). Kubios HRV-heart rate variability analysis software. Computer Methods and Programs in Biomedicine, 113(1), 210-220. https://doi.org/10.1016/j.cmpb.2013.07. 024

Task Force of the European Society of Cardiology and the North American Society of Pacing and Electrophysiology. (1996). Heart rate variability. Standards of measurement, physiological interpretation, and clinical use. European Heart Journal, 17(3), 354-381.

Thome, J., Hauschild, S., Koppe, G., Liebke, L., Rausch, S., Herzog, J. I., Müller-Engelmann, M., Steil, R., Priebe, K., Hermans, D., Schmahl, C., Bohus, M., \& Lis, S. (2018). Generalisation of fear in PTSD related to prolonged childhood maltreatment: An experimental study. Psychological Medicine, 48(13), 2223-2234. https://doi.org/10.1017/S0033291717003713

Thompson, M., \& Dale, S. K. (2021). Gendered racial microaggressions and self-silencing associated with suicidality among black women living with HIV. Journal of Racial and Ethnic Health Disparities. https://doi.org/10.1007/s40615-021-01009-4

Treynor, W., Gonzalez, R., \& Nolen-Hoeksema, S. (2003). Rumination reconsidered: A psychometric analysis. Cognitive Therapy and Research, 27(3), 247-259. https://doi.org/10.1023/A:10239 10315561

Tsuji, H., Venditti, F. J., Manders, E. S., Evans, J. C., Larson, M. G., Feldman, C. L., \& Levy, D. (1994). Reduced heart rate variability and mortality risk in an elderly cohort. The Framingham Heart Study. Circulation, 90(2), 878-883. https://doi.org/10.1161/01. cir.90.2.878

Vaishnav, S., Stevenson, R., Marchant, B., Lagi, K., Ranjadayalan, K., \& Timmis, A. D. (1994). Relation between heart rate variability early after acute myocardial infarction and long-term mortality. The American Journal of Cardiology, 73(9), 653-657. https:// doi.org/10.1016/0002-9149(94)90928-8

van Praag, H., Kempermann, G., \& Gage, F. H. (1999). Running increases cell proliferation and neurogenesis in the adult mouse dentate gyrus. Nature Neuroscience, 2(3), 266-270. https://doi. org $/ 10.1038 / 6368$

Voss, M. W., Prakash, R. S., Erickson, K. I., Basak, C., Chaddock, L., Kim, J. S., Alves, H., Heo, S., Szabo, A. N., White, S. M., Wójcicki, T. R., Mailey, E. L., Gothe, N., Olson, E. A., McAuley, E., \& Kramer, A. F. (2010). Plasticity of brain networks in a randomized intervention trial of exercise training in older adults. Frontiers in Aging Neuroscience, 2, 32. https://doi.org/10.3389/ fnagi.2010.00032

Waldron, E. M., Burnett-Zeigler, I., Wee, V., Ng, Y. W., Koenig, L. J., Pederson, A. B., Tomaszewski, E., \& Miller, E. S. (2021). Mental health in women living with HIV: The unique and unmet needs. Journal of the International Association of Providers of AIDS Care, 20, 2325958220985665. https://doi.org/10.1177/ 2325958220985665

Weathers, F. W., Blake, D. D., Schnurr, P. P., Kaloupek, D. G., Marx, B. P., \& Keane, T. M. (2013). The life events checklist for DSM-5 (LEC-5). PTSD.

Weng, T. B., Pierce, G. L., Darling, W. G., Falk, D., Magnotta, V. A., \& Voss, M. W. (2017). The acute effects of aerobic exercise on the functional connectivity of human brain networks. Brain Plasticity, 2(2), 171-190. https://doi.org/10.3233/BPL-160039

Yanes, P. K., Morse, G., Hsiao, C. B., Simms, L., \& Roberts, J. E. (2012). Autobiographical memory specificity and the persistence of depressive symptoms in HIV-positive patients: Rumination and social problem-solving skills as mediators. Cognition and 
Emotion, 26(8), 1496-1507. https://doi.org/10.1080/02699931. 2012.665028

Zhou, H. X., Chen, X., Shen, Y. Q., Li, L., Chen, N. X., Zhu, Z. C., Castellanos, F. X., \& Yan, C. G. (2020). Rumination and the default mode network: Meta-analysis of brain imaging studies and implications for depression. NeuroImage, 206, 116287. https://doi.org/10.1016/j.neuroimage.2019.116287
Publisher's Note Springer Nature remains neutral with regard to jurisdictional claims in published maps and institutional affiliations. 